\title{
Wasserman, Bonnie S. Cinema for Portuguese Conversation. Newburyport, MA: Focus Publishing, 2009.
}

It is always with excitement that we greet new resources for Portuguese language teaching and learning. Cinema for Portuguese Conversation is especially welcome, for it provides opportunities for language practice while inviting its users to appreciate Lusophone cinema.

Cinema for Portuguese Conversation, written in Brazilian Portuguese, presents a series of activities which lead to discussion and analysis (if somewhat superficial) of each movie. The textbook is designed for intermediate and advanced students, as explained in the Introduction. It presents a total of 14 movies grouped into five different sections that reflect themes such as urban violence, political transition, and the sertão. Most of the movies explored in the book hail from Brazil, one is a Portuguese production (Capitães de Abril) and another takes place in Cape Verde (O Testamento do Senhor Napumoceno).

The book contains a "Movie Vocabulary" section, which supplies learners with cinema-related lexical items. The section "How to Use This Book" lists exercises that appear in most of the chapters. Each chapter contains general information about the movie ("Informação geral"), which includes a brief presentation of the film, brief bios for the director(s) and main actors, and a vocabulary list. An "Antes do filme" section, also included in each chapter, briefly contextualizes the movie and proposes a few pre-viewing questions. Most exercises are, however, in the "Depois do filme" section, which contains several writing and speaking activities. Writing activities include true/false questions, multiple-choice exercises, correlations, cloze exercises, short answers, short essays, and comparisons with other movies. Speaking activities include questions to be answered in pairs or in groups. These questions are interspersed with cultural information in boxes ("Para saber"). An activity entitled "Canto dos Críticos" encourages learners to act as movie critics on a TV show and even suggests videotaping of their 
discussions. Another speaking activity, "Análise de uma cena," helps students dissect one particular scene in each movie. At the end of each chapter we find a reading passage preceded by a few pre-reading questions. Each of these texts is somehow related to the general theme of the movie. These passages can be long (some as long as five pages) and are followed by three to six post-reading questions.

Some of the activities proposed in Cinema for Portuguese Conversation are very good for vocabulary practice and for discussions. Multiple-choice and fill-in-the-blanks activities help learners apply new vocabulary. The essays and the movie comparison activities can lead to potentially exciting pieces produced by learners. Among the speaking activities, "Canto dos Críticos" seems to be the most appropriate for fruitful discussions. While some activities can be very productive, others follow typical "reading/viewing comprehension" patterns: what happens, who does what, how people and things are portrayed. These types of exercises, which are abundant in foreign language textbooks, do not lend themselves to critical analyses of texts (or movies). The questions included in the "Conversa" section, for example, lean toward mere recalling of the movie. The post-reading questions that accompany the "Atividade de leitura" also tend only to verify whether the learner has understood the text, without providing opportunities for questioning, critiquing or relating the text to broader contexts (or even to other points in the chapter).

The activities do not suggest that viewing be interrupted at any point. The teacher may certainly adapt that, if $\mathrm{s} / \mathrm{he}$ so desires, and break up the movie, carrying out certain activities in between. The instructor may also have to pick and choose among the activities and even adapt some for best results in class. Some expansion is especially recommended for activities related to the reading passage. Attention is also needed to spelling and to sentence structure. Even though the publisher had to reprint the book because of errors in the first printing, some have remained. These errors go from mere spelling (among others, "Juazerio" for Juazeiro on p. 12; "pístola" for pistola on pp. 112-113; "esquence" for esquece 
on p. 123; "ditadur" for ditadura on p. 153) to agreement ("o cigarros" on p. 13) to misnomers ("guineanos" for guineenses on p. 149). Interestingly, on page 149 we find both "cabo-verdianos" and "cabo-verdenses" - the latter, naturally, nonexistent in Portuguese. We also find sentences with missing words. On page 12, for example, a text about Corcovado states: "Corcovado significa corcunda, e refere-se ao de 710 metros de altura (ou 2.330 pés)." Given the errors that still permeate the textbook, instructors are advised to read everything carefully and call students' attention to cases that merit it. The publisher would do well to have the whole book carefully reviewed for typos and other such mistakes.

In spite of a few problems, professionals in Portuguese language education now have one more resource at their disposal. Those of us who can teach conversation courses will be happy to use Cinema for Portuguese Conversation, for this tool would not only allow for language practice, but would also be very helpful in inviting students to learn more about certain aspects of Lusophone cultures.

Gláucia V. Silva University of Massachusetts Dartmouth 